\title{
Endoscopic drainage of an infected post-surgical abdominal fluid collection using a lumen-apposing metal stent
}

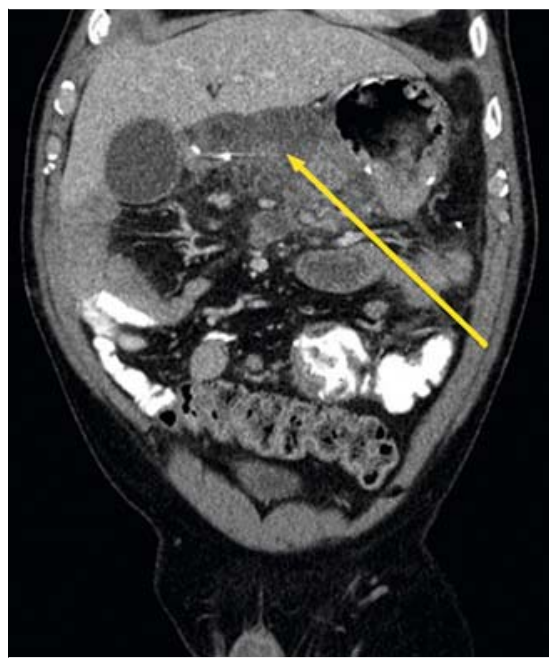

- Fig. 1 A computed tomography scan showed a $7.4 \mathrm{~cm}$ post-surgical abdominal fluid collection (arrow), just medial to the gastrojejunostomy anastomosis, which extended into the porta hepatis.

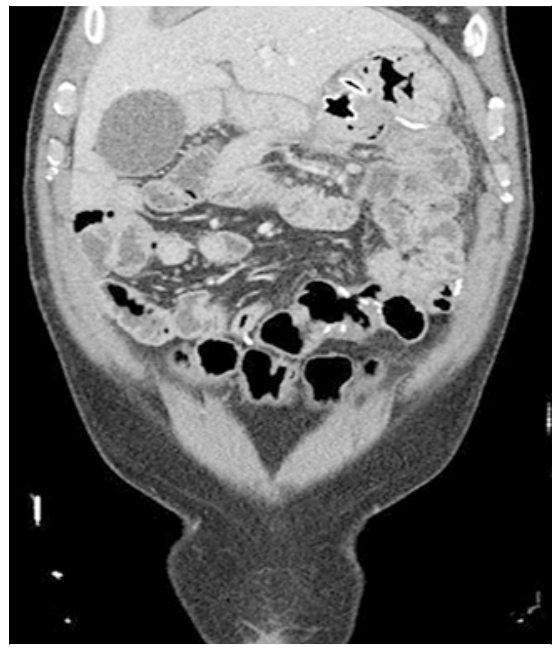

- Fig. 4 A computed tomography scan showed resolution of the post-surgical abdominal fluid collection.

A 63-year-old man with a history of nonsmall cell lung cancer in remission following left upper lobe lobectomy was found to have a $5 \mathrm{~cm}$ mass along the inferior aspect of the stomach that had enlarged from a previous computed tomography

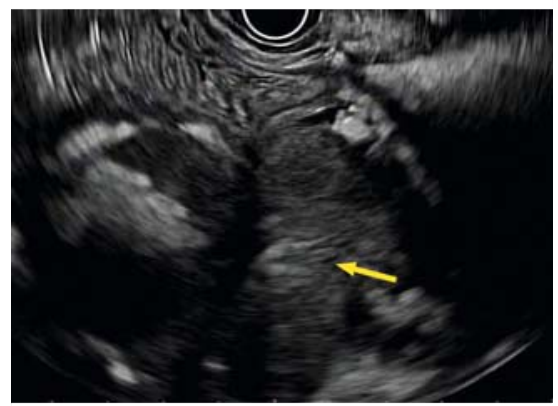

- Fig. 2 Endoscopic ultrasound image of the infected post-surgical abdominal fluid collection (arrow).

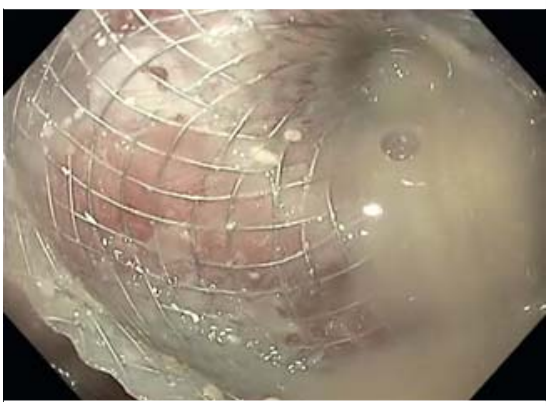

- Fig. 3 A lumen-apposing metal stent placed into the post-surgical abdominal fluid collection resulted in the drainage of frank pus.

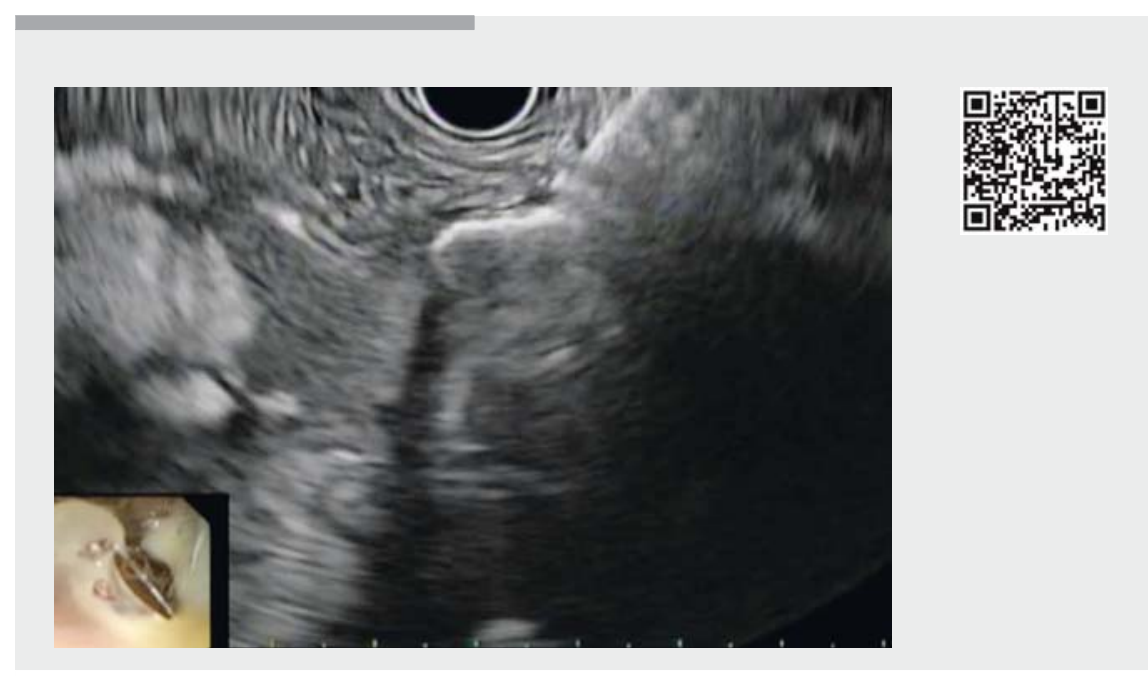

$\checkmark$ Video 1 Placement of a lumen-apposing metal stent to drain an infected post-surgical abdominal fluid collection.

(CT) scan. He underwent a Billroth II gastrectomy with resection of the mass, which was consistent with a metastasis of the primary tumor. Three weeks after abdominal surgery, he developed newonset abdominal pain and fever to 102 degrees Fahrenheit. A CT scan showed a new $7.4 \mathrm{~cm}$ post-surgical abdominal fluid collection (AFC), just medial to the gastrojejunostomy anastomosis, which extended into the porta hepatis ( $\mathbf{F i g . 1}$ ). The fluid was of higher density than simple fluid and was thought to be infected.
The interventional radiology service was consulted for drainage of the infected post-surgical AFC but the window for drainage was not optimal, as the potential drainage paths had intervening bowel or liver. Therefore, our service was consulted for endoscopic ultrasound (EUS)-guided drainage.

Under linear echoendoscopic guidance, the fluid collection was visualized adjacent to the gastrojejunostomy anastomosis, the pancreas, and the liver ( Fig.2). A $15 \times 10 \mathrm{~mm}$ lumen-apposing 
metal stent (LAMS; AXIOS; Boston Scientific, Marlborough, Massachusetts, USA) was placed, under EUS guidance, using an electrocautery-enhanced deliver device ( Video 1). Upon placement, frank pus was seen flowing from the stent ( Fig.3). Within 24 hours, the patient's fever and abdominal pain had resolved. A repeat $C T$ scan 4 weeks later showed the collection had resolved ( $\mathbf{F i g . 4}$ ). The stent was removed at 5 weeks after the initial placement.

Although EUS-guided drainage of postsurgical AFCs has been described using plastic stents [1,2], no literature exists on the use of LAMSs. This case demonstrates that the use of EUS-guided LAMS placement can be successful to drain these collections.

Endoscopy_UCTN_Code_TTT_1AS_2AG

Competing interests

None
The Authors

Arvind J. Trindade ${ }^{1}$, Yonatan J. Hillman ${ }^{1}$, John H. Wang ${ }^{2}$, Petros C. Benias ${ }^{1}$, Larry S. Miller ${ }^{1}$

1 Division of Gastroenterology, Long Island Jewish Medical Center, Hofstra Northwell School of Medicine, Northwell Health System, New Hyde Park, New York, United States

2 Department of Surgery, Long Island Jewish Medical Center, Hofstra Northwell School of Medicine, Northwell Health System, New Hyde Park, New York, United States

\section{Corresponding author}

\section{Arvind J. Trindade, MD}

Long Island Jewish Medical Center, Division of Gastroenterology, Hofstra Northwell School of Medicine, Northwell Health System, 270-05 76th Avenue, New Hyde Park, NY 11040, United States

Fax: +1-718-470-5509

arvind.trindade@gmail.com

\section{References}

[1] Denzer UW, Sioulas AD, Abdulkarim M et al. Endoscopic ultrasound-guided drainage of abdominal fluid collections after pancreatic surgery: efficacy and long-term follow-up. Z Gastroenterol 2016; 54: 1047-1053
[2] Kwon YM, Gerdes H, Schattner MA et al. Management of peripancreatic fluid collections following partial pancreatectomy: a comparison of percutaneous versus EUSguided drainage. Surg Endosc 2013; 27: $2422-2427$

\section{Bibliography}

DOI https://doi.org/10.1055/s-0043-119980

Published online: 9.10.2017

Endoscopy 2017; 49: E319-E320

(c) Georg Thieme Verlag KG

Stuttgart · New York

ISSN 0013-726X

\section{ENDOSCOPY E-VIDEOS}

https://eref.thieme.de/e-videos

回的回 Endoscopy E-Videos is a free access online section, reporting 国: on interesting cases and new techniques in gastroenterological endoscopy. All papers include a high quality video and all contributions are freely accessible online.

This section has its own submission website at https://mc.manuscriptcentral.com/e-videos 